\title{
Occupational exposure to disinfectants and asthma control in US nurses
}

\author{
Orianne Dumas (10 ${ }^{1,2}$, Aleta S. Wiley ${ }^{3}$, Catherine Quinot ${ }^{1,2}$, Raphaëlle Varraso ${ }^{1,2}$, \\ Jan-Paul Zock ${ }^{4,5,6}$, Paul K. Henneberger ${ }^{7}$, Frank E. Speizer ${ }^{3}$, Nicole Le Moual ${ }^{1,2}$ \\ and Carlos A. Camargo $\mathrm{Jr}^{3,8}$
}

Affiliations: 'INSERM U1168, VIMA: Aging and Chronic Diseases, Epidemiological and Public Health Approaches, Villejuif, France. ${ }^{2}$ Université Versailles St-Quentin-en-Yvelines, UMRS 1168, Montigny le Bretonneux, France. ${ }^{3}$ Channing Division of Network Medicine, Dept of Medicine, Brigham and Women's Hospital and Harvard Medical School, Boston, MA, USA. ${ }^{4}$ ISGlobal, Centre for Research in Environmental Epidemiology (CREAL), Barcelona, Spain. ${ }^{5}$ Universitat Pompeu Fabra (UPF), Barcelona, Spain. ${ }^{6} \mathrm{CIBER}$ Epidemiología y Salud Pública (CIBERESP), Madrid, Spain. ${ }^{7}$ Respiratory Health Division, National Institute for Occupational Safety and Health, Morgantown, WV, USA. ${ }^{8}$ Dept of Emergency Medicine, Massachusetts General Hospital and Harvard Medical School, Boston, MA, USA.

Correspondence: Orianne Dumas, INSERM U1168, VIMA: Aging and Chronic Diseases, Epidemiological and Public Health Approaches, 16 avenue Paul Vaillant Couturier, 94807 Villejuif, France.

E-mail: orianne.dumasdinserm.fr

@ERSpublications

Frequent use of disinfectants is associated with poor asthma control in nurses http://ow.ly/Xat330eu1CY

Cite this article as: Dumas O, Wiley AS, Quinot C, et al. Occupational exposure to disinfectants and asthma control in US nurses. Eur Respir J 2017; 50: 1700237 [https://doi.org/10.1183/13993003.00237-2017].

ABSTRACT Disinfectant use has been associated with adverse respiratory effects among healthcare workers. However, the specific harmful agents have not been elucidated. We examined the association between occupational exposure to disinfectants and asthma control in the Nurses' Health Study II, a large cohort of female nurses.

Nurses with asthma were invited in 2014 to complete two questionnaires on their current occupation and asthma (response rate $80 \%$ ). Asthma control was defined by the Asthma Control Test (ACT). Exposure to major disinfectants was evaluated by a job-task-exposure matrix (JTEM).

Analyses included 4102 nurses with asthma (mean age 58 years). Asthma control was poor (ACT score $16-19$ ) in $12 \%$ of nurses and very poor (ACT score $\leqslant 15$ ) in $6 \%$ of nurses. Use of disinfectants to clean medical instruments (19\% exposed) was associated with poorly (OR 1.37; 95\% CI 1.05-1.79) and very poorly (OR 1.88, 95\% CI 1.38-2.56) controlled asthma ( $\mathrm{p}_{\text {trend }}=0.004$, after adjustment for potential confounders). Using JTEM estimates, exposure to formaldehyde, glutaraldehyde, hypochlorite bleach, hydrogen peroxide and enzymatic cleaners was associated with poor asthma control (all $\mathrm{p}_{\text {trend }}<0.05$ ); exposure to quaternary ammonium compounds and alcohol was not.

Use of several disinfectants was associated with poor asthma control. Our findings suggest targets for future efforts to prevent worsening of asthma control in healthcare workers.

This article has supplementary material available from erj.ersjournals.com

Received: Feb 022017 | Accepted after revision: July 152017

Support statement: Centers for Disease Control and Prevention R01 OH-10359; National Institutes of Health UM1 CA176726; Hubert Curien Partnerships for French-Dutch cooperation, French Ministry of Higher Education and Research and OCW Dutch Ministry (Ministerie van Onderwijs, Cultuur en Wetenschap) PHC Van Gogh 33653RF. The research leading to these results has received funding from the People Programme (Marie Curie Actions) of the European Union's Seventh Framework Programme (FP7/2007-2013) under REA grant agreement PCOFUND-GA-2013-609102, through the PRESTIGE programme coordinated by Campus France. Funding information for this article has been deposited with the Crossref Funder Registry.

Conflict of interest: Disclosures can be found alongside this article at erj.ersjournals.com

The content of this work is not subject to copyright. Design and branding are Copyright (CERS 2017 


\section{Introduction}

To achieve and maintain asthma control is the primary target of international asthma management guidelines [1]. However, population-based studies in Europe and the USA have shown that asthma control is suboptimal in $40-50 \%$ of adult patients, with even higher rates among women [2,3]. While asthma management recommendations mainly focus on treatment, the identification and avoidance of exposures contributing to poor asthma control are recognised as important steps in disease management [1]. Nevertheless, few epidemiological studies have focused on determinants of asthma control among adults $[1,4]$.

Workplace exposures contribute to poor asthma control and severe exacerbations [5, 6], and their reduction has been suggested as one of the public health interventions likely to have the greatest effect in improvement of respiratory health [7]. A substantial portion of work-related asthma cases has been identified in the healthcare industry, which is one of the largest employment sectors in the USA and Europe $[8,9]$.

Increased risk of asthma symptoms/exacerbations among healthcare workers is believed to be related in large part to exposure to cleaning products and disinfectants [8, 10-12]. Although some of the chemicals contained in these products (e.g. bleach, quaternary ammonium compounds ("quats") and ammonia) have been associated with current asthma or asthma symptoms/exacerbations, results from epidemiological studies are limited or inconsistent regarding most specific agents [10, 12-14]. This question is of particular importance in healthcare settings as work-related asthma prevention strategies, usually based on avoidance of the harmful agent(s), need to be implemented in accordance with infection control guidelines regarding disinfection procedures in order to protect patients from infections [15].

The Nurses' Health Study II (NHSII) is a large, ongoing, prospective study of US female nurses. In 2014, we initiated a case-control study on asthma nested within NHSII to study occupational determinants of asthma. In a recent publication, we addressed the challenge of assessing exposure to a wide range of disinfectants in this population, for which we developed a job-task-exposure matrix (JTEM) [16]. Here, we investigate the association between occupational exposure to cleaning/disinfection tasks and specific agents and asthma control.

\section{Material and methods \\ Population}

The NHSII began in 1989 when 116430 female registered nurses from 15 US states, aged 25-44 years, completed a questionnaire on their medical history and lifestyle characteristics [17-19]. Follow-up questionnaires have been sent every 2 years since. In 2014, 10618 participants who ever reported physician-diagnosed asthma in biennial questionnaires and were in a nursing job in 2011 were invited to complete two questionnaires: one on occupational exposures and one on asthma (response rate 80\%) (figure 1).

This investigation was approved by the Institutional Review Board at the Brigham and Women's Hospital (Boston, MA, USA).

\section{Asthma}

Participants who reported asthma in biennial questionnaires were categorised on the basis of supplemental asthma questionnaires according to validated case definitions, as described previously [17-19]. We selected participants who reiterated on the supplemental questionnaire that a physician had diagnosed her as having asthma and who reported use of any asthma medication in the past year [17]. Sensitivity analyses were conducted using a more stringent asthma definition, based on the latter criteria and additional report of use of a prescribed long-term preventive medication (i.e. inhaled corticosteroids, cromolyn sodium, nedocromil, salmeterol or theophylline) in the past year. Among them, asthma control was defined using the Asthma Control Test (ACT) score (range 5-25), based on five questions on activity limitations, frequency of symptoms and frequency of use of quick-relief medication in the past 4 weeks [20].

\section{Exposure to disinfectants}

Information on general disinfection tasks (frequency of use of disinfectants to clean surfaces/medical instruments and use of sprays) was collected in the occupational questionnaire $[10,21]$, as described previously [16]. These questions also were asked in the 2013 main questionnaire, i.e. before and independently of the 2014-2015 asthma substudy (figure 1).

Exposure to seven major disinfectants/cleaning products (formaldehyde, glutaraldehyde, hypochlorite bleach, hydrogen peroxide, alcohol, quats and enzymatic cleaners) was evaluated by a nurse-specific JTEM. The JTEM was designed using information collected by questionnaire in a random sample of NHSII participants without asthma $(\mathrm{n}=9073)$, as described in detail elsewhere [16] and in the supplementary 
NHSII main biennial questionnaires

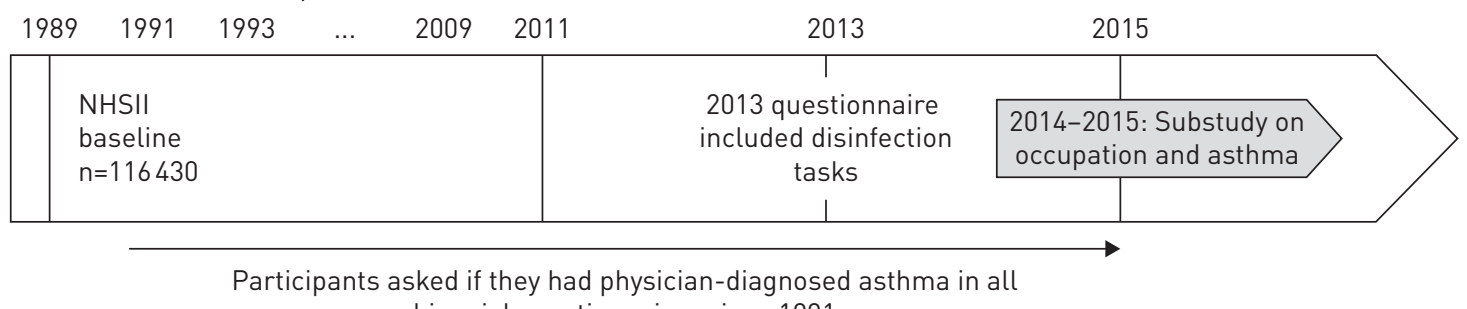
biennial questionnaires since 1991

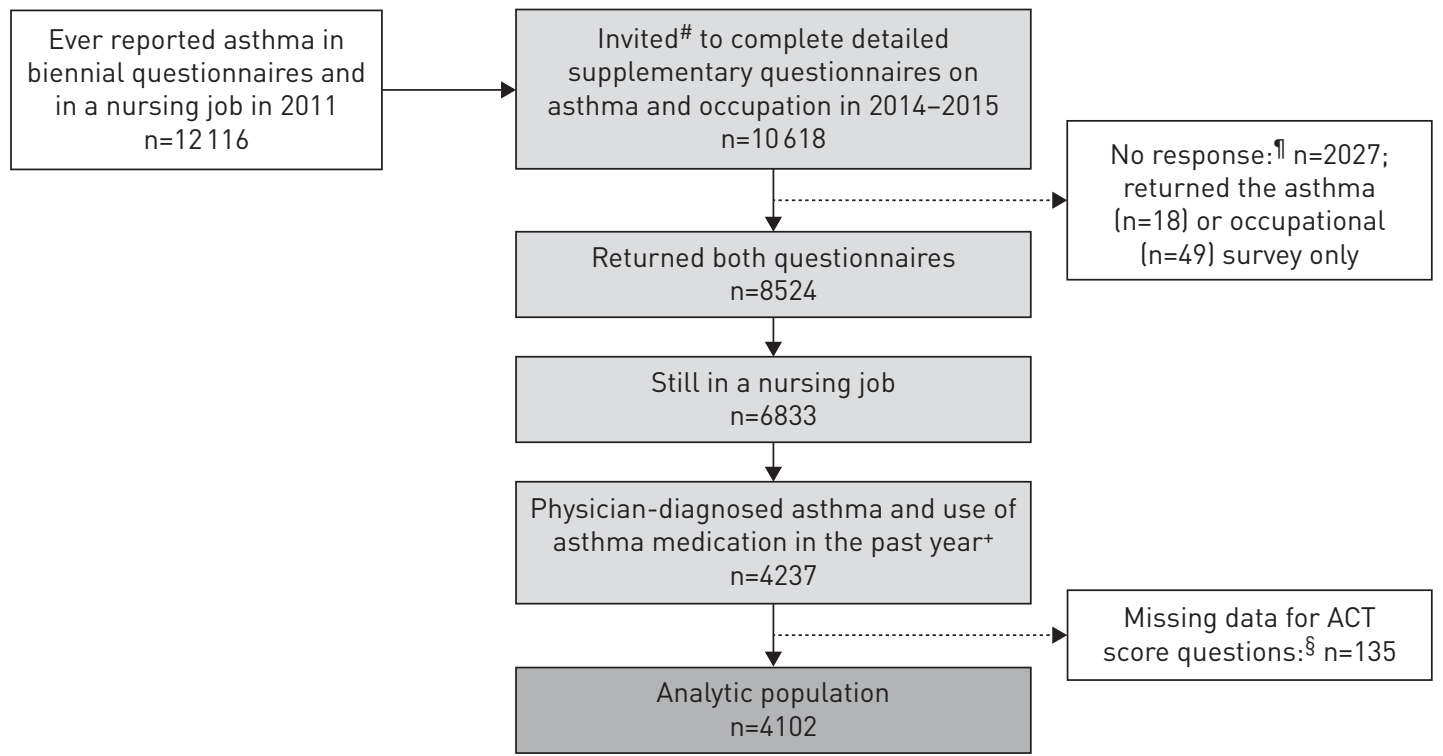

FIGURE 1 Flowchart of the study population. NHSII: Nurses' Health Study II; ACT: Asthma Control Test. In NHSII, the active follow-up rate (number of person-years in the cohort when participants are censored after their last questionnaire response) from 1989 to 2013 was $86 \%$ of the potential person-years. " : women with asthma invited to complete the surveys were selected among women who reported physician-diagnosed asthma in biennial questionnaires, but only recent respondents (i.e. who returned the 2013 or 2015 questionnaires) were invited. The first invite to complete the survey was sent by e-mail to participants with an e-mail address (85\%) and by regular mail to participants without an e-mail address (15\%). After this first attempt (including two e-mail reminders for women with an e-mail address), all nonrespondents received up to two more invites by regular mail. ": nonrespondents were significantly younger and were more often current smokers, obese and non-White than respondents. Nonrespondents reported higher use of disinfectants in 2011 (weekly use of disinfectants to clean surfaces 47\%) than respondents $(43 \%) .^{+}$: participants who reiterated on the supplemental questionnaire that a physician had diagnosed her as having asthma and reported use of any asthma medication in the past year. ${ }^{\S}$ : participants with missing data for ACT score questions did not differ from included participants for age, smoking status, body mass index, race, ethnicity or self-reported use of disinfectants.

material. The JTEM assigned exposure level (low, medium or high) based on combinations of types of nursing jobs and general disinfection tasks ("job-task" axis).

Exposure to eight other products with lower exposure prevalence (ortho-phthalaldehyde, peracetic acid, acetic acid, ammonia, phenolics, ethylene oxide, chloramine-T and "green" products) was not evaluated by the JTEM, but by self-report [16]. Results regarding these eight products are presented in the supplementary material.

\section{Analyses}

Associations between exposure to disinfectants and asthma control were evaluated by logistic regressions. Asthma control (outcome) was classified into four categories based on ACT score (25: controlled; 20-24: partly controlled; 16-19: poorly controlled; $\leqslant 15$ : very poorly controlled) and considered either as a categorical variable or as an ordinal variable. Disinfection tasks were studied using dichotomous variables (task performed 1-3 or 4-7 versus never or $<1$ day(s) per week). Exposure to specific disinfectants according to the JTEM was studied using three-level variables (low, medium or high exposure level). First, we studied exposure to each disinfectant separately. Then, as nurses were classified as exposed to several products, we studied exposure to combinations of several specific products evaluated by the JTEM, for the products found associated with asthma control when studied separately. Analyses were adjusted for age, smoking status, body mass index (BMI), race (White versus other) and ethnicity (Hispanic versus other). A 
two-sided $\mathrm{p}<0.05$ was considered statistically significant. Analyses were run using SAS version 9 (SAS Institute, Cary, NC, USA).

\section{Results}

Of the 8524 participants who returned both questionnaires on asthma and occupation, 6833 were still in a nursing job in 2014-2015 (figure 1). Among them, $n=4237$ reported use of any asthma medication in the past year. Participants with missing data for ACT questions $(n=135)$ were excluded. This yielded a population of 4102 women eligible for analysis. Participants were on average 58 years of age and $70 \%$ were never-smokers. Regarding cleaning/disinfection tasks, $46 \%$ of the nurses reported weekly use of disinfectants to clean surfaces, $19 \%$ reported weekly use of disinfectants to clean medical instruments and $19 \%$ reported weekly use of sprays. Weekly use of disinfectants was associated with younger age $(p=0.001)$, but no significant difference was observed regarding smoking status, BMI, race or ethnicity. The ACT score ranged from 7 to 25 (median (interquartile range) 23 (21-25)). Asthma was controlled in $32 \%$ of nurses, partly controlled in $50 \%$, poorly controlled in $12 \%$ and very poorly controlled in $6 \%$. Women with poor asthma control were more often current or ex-smokers and had a higher BMI (table 1). Descriptions of each of the ACT score components in the study population are presented in table 2.

\section{Cleaning/disinfection tasks and asthma control}

In multivariable models (table 3), weekly use of disinfectants to clean medical instruments was associated with poorly and very poorly controlled asthma (OR 1.37, 95\% CI 1.05-1.79 and OR 1.88, 95\% CI 1.382.56, respectively; $\mathrm{p}_{\text {trend }}<0.001$ ), but no association was observed for the use of disinfectants to clean surfaces. Associations were similar in participants with childhood-onset and adult-onset asthma (age at onset $<18$ versus $\geqslant 18$ years; $p_{\text {interaction }}=0.92$ ) and with or without atopy (defined by report of ever having had hay fever, seasonal allergy or allergic rhinitis; $p_{\text {interaction }}=0.76$ ). Weekly use of sprays was also associated with poorer asthma control $\left(p_{\text {trend }}=0.002\right)$ (table 3 ), in particular sprays used for surface cleaning/disinfection, patient care and air-refreshing sprays (supplementary table E1). When examining the frequency of cleaning/disinfection tasks (supplementary table E2), associations with poor asthma control were generally stronger among nurses with the highest frequency of use (4-7 days per week). However, for spray use, significant associations were observed even among nurses with infrequent use $(<1$ day per week).

We found similar results in sensitivity analyses 1) studying associations between disinfection tasks reported in the 2013 main questionnaire and asthma control evaluated in 2014-2015 (supplementary table E3), and 2) using a more stringent asthma definition (supplementary table E4).

Use of a face mask or other respiratory protection devices when working with disinfectants was reported by $5 \%$ of the participants overall, but was more frequent $(\mathrm{p}=0.03)$ among women with poorer asthma control. Use of latex gloves (24\%) was not associated with asthma control. No significant difference in the association between use of disinfectants to clean instruments and poorer asthma control ( $p_{\text {interaction }} \geqslant 0.40$ ) was observed according to use of respiratory protection devices or to use of latex gloves (supplementary figure E1).

TABLE 1 Characteristics of the participants according to Asthma Control Test (ACT) score, among 4102 female nurses with asthma

\begin{tabular}{|c|c|c|c|c|c|}
\hline & \multicolumn{4}{|c|}{ ACT score } & \multirow[t]{2}{*}{ p-value } \\
\hline & 25 & $20-24$ & $16-19$ & $\leqslant 15$ & \\
\hline Subjects & 1303 (32) & 2035 (50) & 496 (12) & $268(6)$ & \\
\hline Age months & $58.4 \pm 4.4$ & $58.8 \pm 4.3$ & $58.9 \pm 4.2$ & $59.0 \pm 4.2$ & 0.01 \\
\hline Race: non-White & 5 & 6 & 5 & 8 & 0.23 \\
\hline Ethnicity: Hispanic & 2 & 2 & 1 & 1 & 0.49 \\
\hline \multicolumn{6}{|l|}{ Smoking status ${ }^{\#}$} \\
\hline Never-smoker & 70 & 67 & 64 & 61 & 0.01 \\
\hline Ex-smoker & 28 & 29 & 32 & 33 & \\
\hline Current smoker & 2 & 4 & 4 & 6 & \\
\hline \multicolumn{6}{|l|}{ BMI $\mathrm{kg} \cdot \mathrm{m}^{-2 \#}$} \\
\hline$<25.0$ & 33 & 29 & 23 & 18 & $<0.001$ \\
\hline $25.0-29.9$ & 31 & 29 & 28 & 31 & \\
\hline$\geqslant 30.0$ & 36 & 42 & 49 & 51 & \\
\hline
\end{tabular}

Data are presented $\mathrm{n}(\%)$, mean \pm SD or $\%$, unless otherwise stated. BMI: body mass index. ${ }^{\#}$ : in 2013 (main Nurse's Health Study II questionnaire): missing values for smoking status $n=5$ and $B M I n=37$. 
TABLE 2 Description of Asthma Control Test (ACT) score components, among 4102 female nurses with asthma

\begin{tabular}{|c|c|c|c|c|}
\hline & \multicolumn{4}{|c|}{ ACT score ${ }^{\#}$} \\
\hline & 25 & $20-24$ & $16-19$ & $\leqslant 15$ \\
\hline Subjects & 1303 (32) & $2035(50)$ & $496(12)$ & $268(6)$ \\
\hline \multicolumn{5}{|l|}{ ACT score components score $\leqslant 3$} \\
\hline Activity limitations & 0 & 3 & 21 & 56 \\
\hline Shortness of breath & 0 & 6 & 48 & 92 \\
\hline Woken up by asthma symptoms at night & 0 & 5 & 35 & 78 \\
\hline Use of $\beta$-agonist inhaler & 0 & 15 & 66 & 92 \\
\hline Poor self-rated asthma control & 0 & 7 & 54 & 92 \\
\hline
\end{tabular}

Data are presented as $\mathrm{n}(\%)$ for subjects or $\%$ of participants with a score $\leqslant 3$ for a given component lactivity limitations (asthma keeps me from getting as much done at work, school or at home): "some of the time" to "all of the time"; shortness of breath: "3-6 times per week" to "more than once daily"; woken up by asthma symptoms at night: "once/week" to "every night"; use of $\beta$-agonist inhaler: "2 times per week" to "3+ times daily"; self-rated asthma control: "Somewhat controlled" to "Not controlled at all").

\#: the ACT score was based on responses to five questions (components) on activity limitations, frequency of symptoms and frequency of use of quick-relief medication in the last 4 weeks. Each question was scored using a five-point scale (1: poor control to 5: good control). Scores for each question were then summed to give the ACT score (range 5-25).

Specific disinfectants/cleaning products evaluated by the JTEM and asthma control

In multivariable models, using the JTEM estimates, high levels of exposure to formaldehyde ( $p_{\text {trend }}=0.02$ ), glutaraldehyde $\left(\mathrm{p}_{\text {trend }}=0.02\right)$, hypochlorite bleach $\left(\mathrm{p}_{\text {trend }}=0.02\right)$, hydrogen peroxide $\left(\mathrm{p}_{\text {trend }}=0.01\right)$ and enzymatic cleaners $\left(p_{\text {trend }}<0.001\right)$ were significantly associated with poorer asthma control (figure 2 ); quats $\left(p_{\text {trend }}=0.14\right)$ and alcohol $\left(p_{\text {trend }}=0.12\right)$ were not. More detailed results for each category of asthma control are presented in supplementary table E5.

Nurses generally were classified as exposed to several products (i.e. we did not identify subgroups of nurses with exposure to a single product). Based on this observation, we studied a combination of specific products evaluated by the JTEM (table 4). In this analysis, no associations with asthma control were observed among nurses exposed 1) to hypochlorite bleach or hydrogen peroxide but not to the other products, or 2) to

TABLE 3 Associations between self-reported cleaning/disinfection tasks and Asthma Control Test (ACT) score

n

ACT score

\begin{tabular}{|c|c|c|c|c|c|}
\hline $\begin{array}{c}25 \\
\text { (reference) }\end{array}$ & & $20-24$ & & $16-19$ & $\leqslant 15$ \\
\hline $\mathbf{O R}^{\#}$ & $\%$ & $\mathrm{OR}^{\#}(95 \% \mathrm{CI})$ & $\%$ & $\mathrm{OR}^{\#}(95 \% \mathrm{CI})$ & $\mathrm{OR}^{\#}(95 \% \mathrm{CI})$ \\
\hline
\end{tabular}

\begin{tabular}{|c|c|c|c|c|c|c|c|c|c|c|}
\hline \multicolumn{11}{|c|}{ Weekly use of disinfectant } \\
\hline \multicolumn{11}{|c|}{ To clean surfaces } \\
\hline Yes & 1893 & 31 & 1 & 50 & $1.07(0.93-1.23)$ & 12 & $0.96(0.77-1.18)$ & 7 & $1.26(0.96-1.65)$ & 0.36 \\
\hline No (reference) & 3299 & 32 & 1 & 50 & 1 & 12 & 1 & 6 & 1 & \\
\hline Yes & 769 & 28 & 1 & 49 & $1.16(0.96-1.40)$ & 14 & $1.37(1.05-1.79)$ & 9 & $1.88(1.38-2.56)$ & $<0.001$ \\
\hline \multicolumn{11}{|c|}{ Surface and/or instruments } \\
\hline Instruments & 769 & 28 & 1 & 49 & $1.19(0.97-1.44)$ & 14 & $1.29(0.97-1.70)$ & 9 & $1.87(1.34-2.62)$ & $<0.001$ \\
\hline \multicolumn{11}{|l|}{ Weekly use of sprays" } \\
\hline No (reference) & 3301 & 33 & 1 & 50 & 1 & 11 & 1 & 6 & 1 & \\
\hline Yes & 766 & 28 & 1 & 49 & $1.13(0.94-1.36)$ & 15 & $1.50(1.16-1.94)$ & 8 & $1.38(1.00-1.92)$ & 0.002 \\
\hline
\end{tabular}




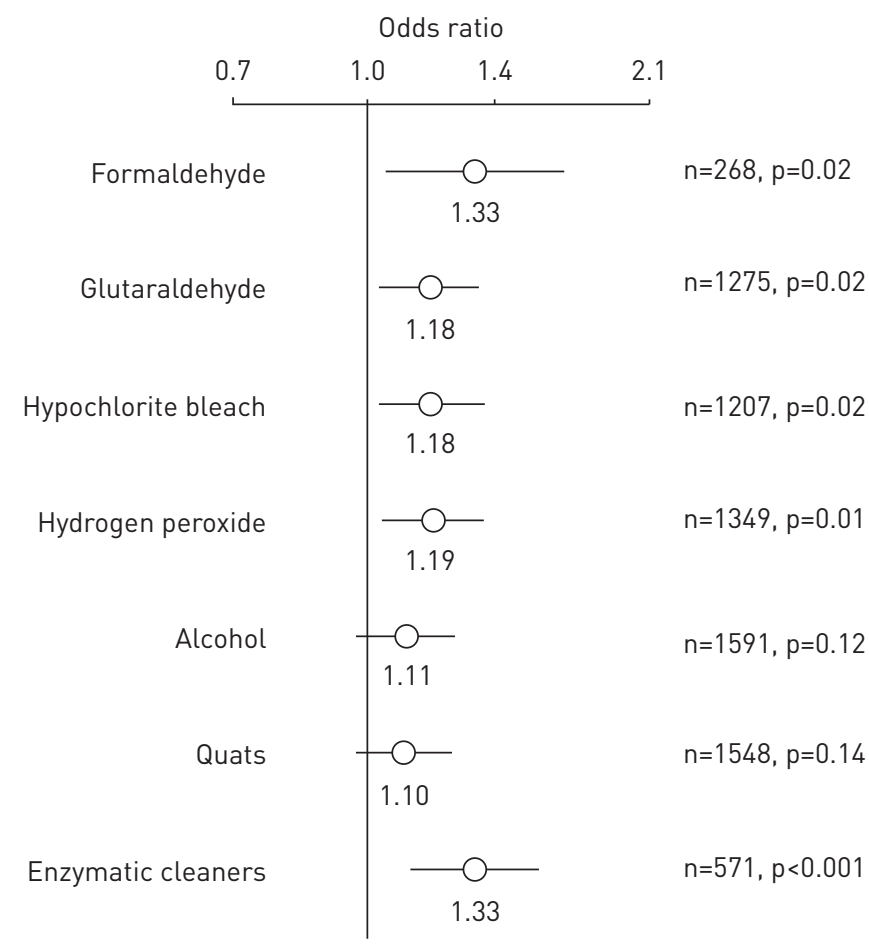

FIGURE 2 Associations between exposure to specific disinfectants/cleaning products evaluated by the jobtask-exposure matrix and asthma control. Quats: quaternary ammonium compounds; n: number exposed. Results are presented as odds ratios and $95 \%$ confidence intervals for a decrease in Asthma Control Test score category (25: controlled; 20-24: partly controlled; 16-19: poorly controlled; $\leqslant 15$ : very poorly controlled), analysed as an ordinal variable (ordinal logistic regression), and adjusted for age, smoking status, body mass index, race and ethnicity. Associations presented compare high versus low exposure level, for each product; no association was observed when comparing medium versus low exposure level.

aldehydes (formaldehyde or glutaraldehyde) but not to the other products. In contrast, a significant increased risk of poorer asthma control was observed ( $p_{\text {trend }}=0.05$ ) among nurses exposed to hypochlorite bleach/ hydrogen peroxide and aldehydes, and among those further exposed to enzymatic cleaners $\left(p_{\text {trend }}=0.001\right)$. The latter exposure combination was observed in participants employed in various nursing jobs (emergency room,

TABLE 4 Associations between combinations of specific disinfectants/cleaning products evaluated by the job-task-exposure matrix (JTEM) and Asthma Control Test (ACT) score

\begin{tabular}{|c|c|c|c|c|c|c|c|c|c|c|}
\hline \multirow{2}{*}{$\begin{array}{l}\text { Exposure combinations } \\
\text { (JTEM estimates) }^{\#}\end{array}$} & \multirow[t]{2}{*}{$\mathbf{n}$} & \multicolumn{8}{|c|}{ ACT score } & \multirow[t]{2}{*}{$\mathrm{p}_{\text {trend }}$-value } \\
\hline & & \multicolumn{2}{|c|}{$\begin{array}{c}25 \\
\text { (reference) }\end{array}$} & \multicolumn{2}{|r|}{$20-24$} & \multicolumn{2}{|r|}{$16-19$} & \multicolumn{2}{|r|}{$\leqslant 15$} & \\
\hline $\begin{array}{l}\text { Low exposure level for all } \\
\text { products (reference) }\end{array}$ & 1832 & 33 & 1 & 49 & 1 & 12 & 1 & 6 & 1 & \\
\hline $\begin{array}{l}\text { 2): High exposure level to } \\
\text { formaldehyde or glutaraldehyde }\end{array}$ & 408 & 34 & 1 & 49 & $1.01(0.79-1.29)$ & 11 & $0.88(0.60-1.29)$ & 6 & $0.96(0.59-1.57)$ & 0.71 \\
\hline 3): $11+21$ & 332 & 28 & 1 & 51 & $1.21(0.92-1.60)$ & 12 & $1.16(0.78-1.74)$ & 9 & $1.71(1.07-2.73)$ & 0.05 \\
\hline $\begin{array}{l}\text { 4): 1)+2)+High exposure } \\
\text { level to enzymatic cleaners }\end{array}$ & 571 & 28 & 1 & 49 & $1.20(0.96-1.50)$ & 14 & $1.35(0.99-1.85)$ & 9 & $1.91(1.31-2.79)$ & 0.001 \\
\hline
\end{tabular}

All exposure variables had <1\% missing values. ": mutually exclusive categories; " : odds ratios from multinomial logistic regression, adjusted for age, smoking status, body mass index, race and ethnicity; ${ }^{+}$: classified as low exposure level for all seven products evaluated by the JTEM

$\S$ : all nurses with high levels of exposure to enzymatic cleaners also had high levels of exposure to glutaraldehyde and/or formaldehyde, and to hydrogen peroxide and/or hypochlorite bleach. Results in italic are statistically significant. 
operating room, outpatient or community, other hospital nursing, or nursing outside hospital) and among them, most (83\%) reported weekly use of disinfectants to clean medical instruments.

In addition, we further examined the associations between exposure to alcohol and quats and asthma control 1) among nurses not exposed to high levels of any of the other five products and 2) among all nurses, in multivariable models further adjusted for the other five products (combined). In both analyses, the absence of association between exposure to alcohol or quats and asthma control was confirmed, with odds ratios close to the null and $\mathrm{p}_{\text {trend }}>0.30$.

\section{Discussion}

In this study of 4102 US female nurses with asthma, disinfection tasks, in particular disinfection of medical instruments, were associated with poor asthma control. We found increased risks of poor asthma control associated with exposure to glutaraldehyde, formaldehyde, enzymatic cleaners, hypochlorite bleach and hydrogen peroxide, in particular for nurses exposed to several of these products. Exposure to quats and alcohol was not associated with poor asthma control.

To the best of our knowledge, this is the first time that asthma control has been studied in relation to occupational exposure to disinfectants among a large cohort of healthcare workers. Asthma was well-characterised in this population of nurses; a previous validation study in NHSII indeed confirmed $95 \%$ of the nurses' reports of doctor-diagnosed asthma [17]. Moreover, we evaluated asthma control using a standardised and validated definition (ACT), integrating the main domains of asthma control (symptoms, use of rescue therapy, sleep interference and activity limitations) [1, 22]. Many studies on work-related asthma have focused on distinguishing risk factors for occupational asthma (i.e. new-onset asthma caused by occupational exposure) and work-exacerbated asthma (worsening of pre-existing asthma) $[23,24]$. In the current study, the association between use of disinfectants and poor asthma control was similar among nurses with childhood-onset (i.e. pre-existing) and adult-onset (i.e. potentially caused by occupational exposures) asthma. Although the distinction between occupational and work-exacerbated asthma is important for legal considerations (workers' compensation), it may be less relevant from a public health perspective as both occupational and work-exacerbated asthma have long-term socioeconomic and health consequences [25]. To minimise risk of exacerbations and accelerated lung function decline in workers, experts have called for research on occupational exposures contributing to poor asthma control [6]. Our results are consistent with a few recent studies showing that exposure to occupational asthmagens [5, 26, 27], and in particular cleaning agents [5, 28], is associated with uncontrolled asthma. Mechanisms by which disinfectants and cleaning products impact respiratory health remain unclear and require further research [11]. Some products (e.g. enzyme-based products) have sensitising potential, but most agents are assumed to act as respiratory irritants [11], and may cause injury of the airway epithelium, oxidative stress and long-lasting neurogenic inflammation [23, 24, 29]. Regardless of the exact mechanisms, our results support the need to consider occupation and potential exposure to disinfectants in clinical practice to improve management of patients with asthma [6,30].

Identifying the specific tasks and agents associated with poor asthma control is of particular importance to improve asthma management among healthcare workers. We found that medical instrument disinfection was associated with poor asthma control, pointing toward a role of high-level disinfectants used on critical or semicritical items [15]. We did not find evidence of an association between use of disinfectants to clean surfaces and asthma control, although this type of task has been associated with increased risk of physician-diagnosed asthma in a study of healthcare workers in Texas in the USA [14]. Few epidemiological studies have investigated the relationship between specific cleaning agents and disinfectants and asthma outcomes in healthcare workers, and they were limited in terms of number/ variety of specific products studied and attempts to control for correlated exposures $[10,12,13]$. In the current study, although we could not fully study the independent effect of each chemical (because we did not find subgroups of nurses with exposure to a single product), we attempted to identify combinations of exposures associated with greater risk of poor asthma control. We found particularly increased risk among nurses with exposure to aldehydes (formaldehyde or glutaraldehyde), hypochlorite bleach or hydrogen peroxide and enzymatic cleaners, based on the JTEM estimates. Formaldehyde has been known as an asthmagen for a long time [31]. Glutaraldehyde and hydrogen peroxide also have been suggested as agents implicated in occupational asthma among healthcare workers in a smaller study in Canada or case reports in France and the USA [32-34]. Associations between the use of hypochlorite bleach and asthma outcomes have been reported in European studies [11]. Enzymatic products are used to clean items before high-level disinfection or sterilisation. A role of enzymatic cleaners in asthma among healthcare workers was suspected based on case reports in healthcare settings and earlier reports in the detergent industry in the UK $[35,36]$. We believe this is the first time these agents have been implicated in an epidemiological study. Finally, a strong association between exposure to quats and physician-diagnosed asthma was 
reported in a study of 543 French healthcare workers, in contrast to our results [12]. Exposure to quats is particularly difficult to evaluate [21]. In our study, although we integrated information collected on product brand names and review of the corresponding safety date sheets, as recommended [12], when creating the JTEM, exposure to quats may still be underestimated. However, any trend for an association between exposure to quats and poor asthma control disappeared after controlling for exposure to other products.

Apart from the active ingredients, specific types of tasks and product application procedures may influence respiratory health effects and are interesting targets for interventions [15]. Spraying has been associated with increased risk of asthma or respiratory symptoms, likely because of the higher potential for inhalation exposure when using sprays [13]. Consistently, we found in the current study that use of sprays was associated with poor asthma control.

Major strengths of our study included the large sample size and the use, for the first time, of a nurse-specific JTEM. Most existing studies on the relationship between the use of specific cleaning/ disinfecting products and asthma relied on self-reported exposures, raising the issue of both nondifferential and differential misclassification bias, potentially leading to bias either toward or away from the null [21]. Use of job-exposure matrices (JEMs) is generally favoured in occupational epidemiology for exposure assessment in large populations [37]. As nursing jobs are heterogeneous (i.e. nurses with the same job title may perform different tasks), we showed that taking into account disinfection tasks (within job variability) in exposure assessment by creating a JTEM provides better exposure estimates than a JEM, i.e. reduces exposure misclassification [16]. In the present study, we observed associations between exposure to several products, as evaluated by the JTEM, and asthma control. However, as we used questionnaires to evaluate disinfection tasks, some of our results may be subject to differential misclassification bias (i.e. differential recall of exposure according to asthma outcomes, possibly leading to spurious associations). To address this question, we performed a sensitivity analysis studying prospectively the associations between disinfection tasks in 2013 and asthma control in 2014-2015, and found similar results, suggesting that differential misclassification bias is not likely a major explanation for our findings regarding disinfection tasks. Potential for recall bias in the association between self-reported cleaning/disinfection tasks and asthma has been formally evaluated in the Texas healthcare workers study; although the authors warn against the possibility of such bias, only a slight effect was reported [38]. Finally, other studies where evaluation of disinfectant exposure was based on expert assessment (i.e. independent of participant recall) have reported associations with current or physician-diagnosed asthma [12, 13].

The cross-sectional design of our study also prevents addressing the question of a healthy worker effect, i.e. a tendency of workers with a history of asthma or more severe asthma to avoid or leave jobs involving harmful exposures such as disinfectants. Such an effect has been suggested in a previous analysis of this cohort of women who have been in nursing jobs for several decades and may cause underestimation of some associations in the current study [19]. However, it is notable that we observed strong positive associations between exposure to several disinfectants and poor asthma control despite a potential healthy worker effect, which will typically bias associations toward the null [19]. In future studies, assessing the association between disinfectant exposures and asthma control among healthcare workers at an earlier career stage, and the impact of exposure duration, would be of particular interest.

Finally, in our study, exposure to eight specific disinfectants could not be evaluated using the JTEM as exposure prevalence was too low $(<10 \%$ with weekly exposures in all nursing job types) to create such estimates, which was a limitation [16]. However, we evaluated risks associated with exposure to major disinfectants and cleaning agents used in healthcare settings [39]. Our results also confirmed that latex exposure was no longer the major concern for respiratory health among healthcare workers, as suggested recently [8], most likely because of the reduction in the use of powdered latex gloves.

In our study, the use of respiratory protection devices when handling disinfectants was limited (in accordance with a previous report [39]), although it was more frequent among nurses with poor asthma control. Even with more than 4000 nurses, because of low numbers, we could not determine whether use of respiratory protection devices had an impact on the association between disinfectant use and asthma control. However, use of personal protective equipment is generally not considered as the most effective measure of work-related asthma prevention. Elimination of hazardous substances and replacement with safer alternatives is preferred [15]. In accordance with earlier reports, we found that many chemicals in healthcare settings may have an impact on respiratory health, including products (e.g. hydrogen peroxide) used as alternatives to known asthmagens (e.g. aldehydes) [39]. Our results thus support the investigation of emerging nonchemical technologies for disinfection (e.g. steam, ultraviolet light) as a potential alternative to chemical disinfection and further research on green cleaning, integrating health risk reduction among the products' standards $[15,40]$. 
The USA has more than 3 million registered nurses and over 12 million workers are employed in the healthcare industry [41]; in Europe, healthcare workers represents $\sim 10 \%$ of the workforce [8]. We found that the use of several specific disinfectants by nurses was associated with poor to very poor asthma control. Our findings highlight the urgency of integrating occupational health considerations in guidelines for cleaning and disinfection in healthcare [15]; they suggest targets for future efforts to improve asthma management in a large group of workers.

\section{Acknowledgements}

The Nurses' Health Study II (NHSII) is coordinated at the Channing Division of Network Medicine, Brigham and Women's Hospital, Boston, MA, USA. We would like to thank the participants and staff of NHSII for their valuable contributions. In particular, we would like to thank Lisa Abramovitz, Krislyn Boggs, Charlotte Marsh, Chidiogo Onwuakor and Christina Staffiere (Channing Division of Network Medicine, Brigham and Women's Hospital, Boston, MA, USA) for their help with data cleaning and management. We also thank Francine Kauffmann (INSERM, Villejuif, France) for her participation in the study conception.

The findings and conclusions in this report are those of the authors and do not necessarily represent the views of the National Institute for Occupational Safety and Health.

Author contributions: O. Dumas contributed to the study conception, the acquisition, analysis and interpretation of the data, and primary manuscript preparation. A.S. Wiley was involved in the acquisition and interpretation of the data, and critical revision of the manuscript. C. Quinot, R. Varraso, J-P. Zock and P.K. Henneberger were involved in the data interpretation and critical revision of the manuscript. F.E. Speizer contributed to the acquisition and interpretation of the data, and critical revision of the manuscript. N. Le Moual contributed to the study conception, data interpretation and critical revision of the manuscript. C.A. Camargo Jr participated in the study conception, acquisition of the data, data interpretation and critical revision of the manuscript. All authors approved the final version of the manuscript and agreed to be accountable for all aspects of the work in ensuring that questions related to the accuracy or integrity of any part of the work are appropriately investigated and resolved.

\section{References}

1 Papaioannou AI, Kostikas K, Zervas E, et al. Control of asthma in real life: still a valuable goal? Eur Respir Rev 2015; 24: 361-369.

2 Braido F, Brusselle G, Guastalla D, et al. Determinants and impact of suboptimal asthma control in Europe: the International Cross-Sectional And Longitudinal Assessment On Asthma Control (LIAISON) study. Respir Res 2016; 17: 51.

3 Fuhlbrigge A, Reed ML, Stempel DA, et al. The status of asthma control in the U.S. adult population. Allergy Asthma Proc 2014; 30: 529-533.

4 Schatz M. Predictors of asthma control: what can we modify? Curr Opin Allergy Clin Immunol 2012; 12: 263-268.

5 Le Moual N, Carsin A-E, Siroux V, et al. Occupational exposures and uncontrolled adult-onset asthma in the European Community Respiratory Health Survey II. Eur Respir J 2014; 43: 374-386.

Boulet L-P. Asthma control in the workplace. Eur Respir J 2014; 43: 319-321.

7 Beasley R, Semprini A, Mitchell EA. Risk factors for asthma: is prevention possible? Lancet 2015; 386: 1075-1085.

8 Wiszniewska M, Walusiak-Skorupa J. Occupational allergy: respiratory hazards in healthcare workers. Curr Opin Allergy Clin Immunol 2014; 14: 113-118.

9 White GE, Mazurek JM, Moorman JE. Asthma in health care workers: 2008 and 2010 Behavioral Risk Factor Surveillance System Asthma Call-Back Survey. J Occup Environ Med 2013; 55: 1463-1468.

10 Arif AA, Delclos GL. Association between cleaning-related chemicals and work-related asthma and asthma symptoms among healthcare professionals. Occup Environ Med 2012; 69: 35-40.

11 Siracusa A, De Blay F, Folletti I, et al. Asthma and exposure to cleaning products - a European Academy of Allergy and Clinical Immunology task force consensus statement. Allergy 2013; 68: 1532-1545.

12 Gonzalez M, Jégu J, Kopferschmitt M-C, et al. Asthma among workers in healthcare settings: role of disinfection with quaternary ammonium compounds. Clin Exp Allergy 2014; 44: 393-406.

13 Dumas O, Donnay C, Heederik D, et al. Occupational exposure to cleaning products and asthma in hospital workers. Occup Environ Med 2012; 69: 883-889.

14 Arif AA, Delclos GL, Serra C. Occupational exposures and asthma among nursing professionals. Occup Environ Med 2009; 66: 274-278.

15 Quinn MM, Henneberger PK, Braun B, et al. Cleaning and disinfecting environmental surfaces in health care: toward an integrated framework for infection and occupational illness prevention. Am J Infect Control 2015; 43: 424-434.

16 Quinot C, Dumas O, Henneberger PK, et al. Development of a job-task-exposure matrix to assess occupational exposure to disinfectants among US nurses. Occup Environ Med 2017; 74: 130-137.

17 Camargo CA Jr, Weiss ST, Zhang S, et al. Prospective study of body mass index, weight change, and risk of adult-onset asthma in women. Arch Intern Med 1999; 159: 2582-2588.

18 Le Moual N, Varraso R, Zock JP, et al. Are operating room nurses at higher risk of severe persistent asthma? The Nurses' Health Study. J Occup Environ Med 2013; 55: 973-977.

19 Dumas O, Varraso R, Zock JP, et al. Asthma history, job type and job changes among US nurses. Occup Environ Med 2015; 72: 482-488.

20 Schatz M, Sorkness CA, Li JT, et al. Asthma Control Test: reliability, validity, and responsiveness in patients not previously followed by asthma specialists. J Allergy Clin Immunol 2006; 117: 549-556.

21 Donnay C, Denis MA, Magis R, et al. Under-estimation of self-reported occupational exposure by questionnaire in hospital workers. Occup Environ Med 2011; 68: 611-617.

22 Cloutier MM, Schatz M, Castro M, et al. Asthma outcomes: composite scores of asthma control. J Allergy Clin Immunol 2012; 129: S24-S33.

23 Tarlo SM, Lemiere C. Occupational asthma. N Engl J Med 2014; 370: 640-649. 
24 Dumas O, Le Moual N. Do chronic workplace irritant exposures cause asthma? Curr Opin Allergy Clin Immunol 2016; 16: 75-85.

25 Lemière C, Boulet LP, Chaboillez S, et al. Work-exacerbated asthma and occupational asthma: do they really differ? J Allergy Clin Immunol 2013; 131: 704-710.

26 Marincu I, Frent S, Tomescu MC, et al. Rates and predictors of uncontrolled bronchial asthma in elderly patients from western Romania. Clin Interv Aging 2015; 10: 963-967.

27 Lindström I, Suojalehto H, Pallasaho P, et al. Middle-aged men with asthma since youth. J Occup Environ Med 2013; 55: 917-923.

28 Dumas O, Siroux V, Luu F, et al. Cleaning and asthma characteristics in women. Am J Ind Med 2014; 57: 303-311.

29 Dumas O, Matran R, Zerimech F, et al. Occupational exposures and fluorescent oxidation products in 723 adults of the EGEA study. Eur Respir J 2015; 46: 258-261.

30 Lemière C, To T, De Olim C, et al. Outcome of work-related asthma exacerbations in Quebec and Ontario. Eur Respir J 2015; 45: 266-268.

31 Chan-Yeung M, Malo JL. Aetiological agents in occupational asthma. Eur Respir J 1994; 7: 346-371.

32 Dimich-Ward H, Lee Wymer M, Chan-Yeung M. Respiratory health survey of respiratory therapists. Chest 2004; 126: $1048-1053$.

33 Cristofari-Marquand E, Kacel M, Milhe F, et al. Asthma caused by peracetic acid-hydrogen peroxide mixture. J Occup Health 2007; 49: 155-158.

34 Hawley B, Casey ML, Cox-Ganser JM, et al. Respiratory symptoms and skin irritation among hospital workers using a new disinfection product - Pennsylvania, 2015. MMWR Morb Mortal Wkly Rep 2016; 65: 400-401.

35 Adisesh A, Murphy E, Barber CM, et al. Occupational asthma and rhinitis due to detergent enzymes in healthcare. Occup Med 2011; 61: 364-369.

36 Cullinan P, Harris JM, Taylor AJN, et al. An outbreak of asthma in a modern detergent factory. Lancet 2000; 356: 1899-1900.

37 Loomis D. Towards population-wide exposure assessment. Occup Environ Med 2012; 69: 455-456.

38 Delclos GL, Gimeno D, Arif AA, et al. Occupational exposures and asthma in health-care workers: comparison of self-reports with a workplace-specific job exposure matrix. Am J Epidemiol 2009; 169: 581-587.

39 Henn SA, Boiano JM, Steege AL. Precautionary practices of healthcare workers who disinfect medical and dental devices using high-level disinfectants. Infect Control Hosp Epidemiol 2015; 36: 180-185.

40 Garza JL, Cavallari JM, Wakai S, et al. Traditional and environmentally preferable cleaning product exposure and health symptoms in custodians. Am J Ind Med 2015; 58: 988-995.

41 US Bureau of Labor Statistics. Occupational Employment and Wages Summary. 2015. www.bls.gov/news.release/ ocwage.nr0.htm Date last accessed: January 31, 2017. 